Published in final edited form as:

Diabetologia. 2014 October ; 57(10): 2117-2125. doi:10.1007/s00125-014-3326-5.

\title{
Denatonium induces secretion of glucagon-like peptide-1 through activation of bitter taste receptor pathways
}

\author{
Ki-Suk Kim, \\ Department of Biochemistry, College of Korean Medicine, Kyung Hee University, Hoegi-Dong, \\ Dongdaemun-Gu, Seoul 130-701, Republic of Korea \\ Josephine M. Egan, and \\ National Institute on Aging, National Institutes of Health, Baltimore, MD, USA \\ Hyeung-Jin Jang \\ Department of Biochemistry, College of Korean Medicine, Kyung Hee University, Hoegi-Dong, \\ Dongdaemun-Gu, Seoul 130-701, Republic of Korea
}

\begin{abstract}
Aims/hypothesis-This study was designed to ascertain whether human enteroendocrine cells express bitter taste receptors, and whether activation of these receptors with bitter-tasting ligands induces secretion of glucagon-like peptide-1 (GLP-1) and peptide YY (PYY).
\end{abstract}

\begin{abstract}
Methods-We used human enteroendocrine NCI-H716 cells, isolated duodenal segments from mice, and whole mice as our experimental systems for investigating stimuli and mechanisms underlying GLP-1- and PYY-stimulated release. We measured hormone levels by ELISA and determined bitter taste receptor expression by real-time quantitative PCR. We adopted a pharmacological approach using inhibitors and enhancers of downstream signalling pathways known to be involved in bitter taste transduction in taste bud cells to investigate these pathways in NCI-H716 cells.
\end{abstract}

Results-Using a pharmacological approach, we identified signalling pathways triggered by the denatonium benzoate (DB)-activated bitter receptors. This involved activation of a-gustducin (Gagust) - the specific G-protein subunit that is also present in taste bud cells-reduction of intracellular cAMP levels and enhancement of phospholipase C (PLC) activity, which ultimately led to increased intracellular calcium concentrations and hormone release. Gavage of DB, followed by gavage of glucose, to $d b / d b$ mice stimulated GLP-1 and subsequent insulin secretion, leading to lower blood glucose levels.

Conclusions/interpretation-Our study demonstrates that activation of gut-expressed bitter taste receptors stimulates GLP-1 secretion in a PLC-dependent manner. In diabetic mice, DB (a

Correspondence to: Hyeung-Jin Jang.

Electronic supplementary material The online version of this article (doi:10.1007/s00125-014-3326-5) contains peer-reviewed but unedited supplementary material, which is available to authorised users.

Duality of interest The authors declare that there is no duality of interest associated with this manuscript.

Contribution statement H-JJ designed the study, performed in vitro experiments, analysed the data, and wrote the manuscript K-SK performed in vivo experiments, analysed and interpreted the data and wrote the manuscript. JME designed the study. All authors contributed to critical revision of the manuscript and approved the final version. H-JJ is the guarantor of this work. 
ligand of bitter taste receptor cells), when given via gavage, lowers blood glucose levels in diabetic mice after oral glucose administration, through increased secretion of GLP-1.

\section{Keywords}

Bitter taste receptor; GLP-1; Incretin; PYY; Type 2 diabetes mellitus; a-gustducin

\section{Introduction}

There are five distinct tastes—bitter, sweet, umami, sour and salty—and distinguishing between them is critical for determining the nutritive and toxic qualities of ingested material $[1,2]$. Taste receptors for bitter, sweet and umami are activated when a tastant interacts with specialised G-protein-coupled receptors on taste cells in the taste buds present in the tongue and oropharynx [3]. These G-protein-coupled taste receptors can be divided into two groups: the superfamily of bitter taste receptors (TAS2Rs), and sweet and umami taste receptors (TAS1Rs). There are approximately 25 known human TAS2Rs [4] and three TASIRs (R1, R2 and R3). Unlike bitter taste receptors, which function as monomers or homomultimers, sweet receptors function as heterodimers [5]. Although much work remains to elucidate the full pathways for bitter, sweet and umami modulation in taste cells, significant progress has been made in recent years. All of these receptors interact with the specific $\mathrm{Ga}$ subunit agustducin (Gagust), which is critical to the transduction of taste components [6, 7]. In taste cells, coupling of Gagust to activated bitter taste receptors stimulates phosphodiesterase (PDE), which subsequently decreases intracellular cAMP levels [1]. In addition, the released $\mathrm{G} \beta 3$ and $\mathrm{G} \gamma_{13}$ subunits activate phospholipase (PLC) $\beta 2$, causing the generation of diacylglycerol (DAG) and inositol 1,4,5-trisphosphate ( $\left.\mathrm{IP}_{3}\right)$, two important mediators of calcium release [8]. The release of calcium from internal stores, in turn, induces the opening of cation channels and calcium influx, thereby resulting in neurotransmitter release and regulation of gene expression $[1,6]$.

Outside of the specialised taste cells within the taste buds, Gagust as well as $G \beta_{3}$ and $G \gamma_{13}$ are expressed in enteroendocrine L cells of the gastrointestinal tract [9]. Moreover, both TASIRs $[10,11]$ and TAS2Rs exist outside of taste buds, because they are present in rodent and human gut, and in the mouse and human STC-1 and NCI-H716 enteroendocrine cell lines [12-14].

The L cells secrete glucogen-like peptide (GLP-1), GLP-2 and peptide YY (PYY) in response to the presence of glucose, oligopeptides and NEFA in the gut $[11,15,16]$. Using an electrophysiological approach, Gribble and coworkers have shown that glucose and certain amino acids can trigger both electrical activity and GLP-1 secretion from the GLUTag cell line [17-19]. In addition, activating TASIRs in rodent gut and NCI-H716 cells also resulted in GLP secretion [11].

We have reported that bitter tastants stimulate GLP-1 secretion from human enteroendocrine NCI-H716 cells [20,21], accompanied by upregulation of PDE and $\mathrm{IP}_{3}$ receptor mRNA expression [21]. Furthermore, bitter tastant-mediated GLP-1 secretion requires activation of Gagust in the cells [20]. We therefore hypothesised that human enteroendocrine L cells would secrete GLP-1 and PYY in response to activation of these receptors. GLP-1 has been 
extensively studied because of its glucose-dependent insulinotropic properties, and exenatide, a potent agonist of GLP-1 receptors, is now a treatment for type 2 diabetes [22, 23]. Both GLP-1 and PYY also have other physiologically significant functions of relevance to obesity and type 2 diabetes: they slow gastric emptying [24-26] and act as satiety factors $[27,28]$. To investigate whether activation of bitter taste receptors in L cells induces GLP-1 and PYY secretion, we examined NCI-H716 human enteroendocrine cells and found that they express bitter taste receptors, the receptors are coupled to Gagust, and their activation elicits orchestrated hormone release.

We also hypothesised that the stimulation of GLP-1 secretion through activation of gutexpressed bitter taste receptors in vivo would decrease blood glucose levels through the insulinotropic effect of GLP-1. Therefore, we performed OGTT after oral administration of bitter agonist to $d b / d b$ mice, and measured blood glucose and plasma GLP-1 and insulin levels in a time-dependent manner.

\section{Methods}

\section{Culture of $\mathrm{NCl}-\mathrm{H} 716$ cells and secretion studies}

NCI-H716 cells were maintained in suspension culture as described by the American Type Culture Collection (Manassas, VA, USA). Two days before the experiments, cells were seeded into 24-well culture plates precoated with Matrigel [9]. Denatonium benzoate (DB; $1,2,5$ and $10 \mathrm{mmol} / \mathrm{l})$, quinine $(0.1,0.2,0.5,1$ and $2 \mathrm{mmol} / \mathrm{l})$ and DMSO were purchased from Sigma-Aldrich (St Louis, MO, USA). Cells were incubated in $5 \% \mathrm{CO}_{2}$ for $1 \mathrm{~h}$ at $37^{\circ} \mathrm{C}$ with different test agents or with $1 \%$ DMSO as the vehicle. The culture medium was collected for the measurement of GLP-1 and PYY by ELISA and RIA (Linco Research, St Charles, MO, USA), respectively, and normalised to protein content [8, 11, 29]. GLP-1 and PYY ELISAs (EMD Millipore, Billerica, MA, USA) were performed as described in the manufacturer's guide. GLP-1 concentrations in each sample were measured with a Fluoroskan Ascent FL machine (Thermo Fisher Scientific, Vantaa, Finland). The lowest level of GLP-1 that can be detected by the assay is $2 \mathrm{pmol} / \mathrm{l}$, and the lowest level for the PYY assay is $6.5 \mathrm{pg} / \mathrm{ml}$.

\section{CAMP ELISA}

NCI-H716 cells were treated with forskolin $(10 \mu \mathrm{mol} / \mathrm{l})$ and SQ22536 $(10 \mu \mathrm{mol} / \mathrm{l})($ both from Sigma-Aldrich), quinine ( $2 \mathrm{mmol} / \mathrm{l}$ ) and vehicle for $15 \mathrm{~min}$. DB was added to the cells, and medium collected thereafter in a time-dependent manner (1, 5,10 and $15 \mathrm{~min})$. The cells were lysed with $0.1 \mathrm{~mol} / 1 \mathrm{HC} 1$, and intracellular cAMP was assayed by ELISA (Enzo Life Sciences, Farmingdale, NY, USA) according to the manufacturer's guide. The results were normalised to protein concentration.

\section{Conventional PCR of $\mathrm{NCl}-\mathrm{H} 716$ cells}

Total RNA was extracted using Trizol (Invitrogen, Carlsbad, CA, USA), and conventional PCR was performed as previously described [11]. The primers used are listed in electronic supplementary material (ESM) Table 1. 


\section{Real-time PCR of $\mathrm{NCl}-\mathrm{H} 716$ cells}

Expression of bitter taste receptors in NCI-H716 cells was determined with real-time quantitative PCR as described in the manufacturer's guide (Life Technologies, Grand Island,

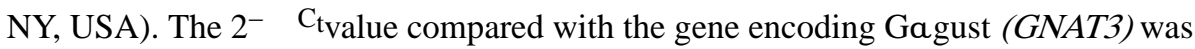
determined using StepOne software (Life Technologies). GAPDH was used as an endogenous control. The results are from three to five individual experiments performed in triplicate. Information on the primers used in real-time PCR is given in ESM Table 2.

\section{Small interfering (si)RNA preparation and $\mathrm{NCl}-\mathrm{H} 716$ cell transfection}

The predesigned siRNA duplexes for knockdown of Gagust (product name 1175215 duplex), TAS2R4 (1148389), TAS2R43 (1148345) and TAS2R46 (1148361) were purchased from Bioneer (Daejeon, South Korea). A scrambled negative control siRNA was also purchased from Bioneer. Transfection with siRNA duplexes was performed with Lipofectamine RNAiMAX reagent (Invitrogen) as previously described [11].

\section{Calcium imaging}

NCI-H716 cells were seeded on a clear-bottom 96-well black plate (Corning, Tewksbury, MA, USA). After differentiation, the medium was replaced with PBS and the mixture was incubated for $30 \mathrm{~min}$ with fura-2 AM dye as described previously [5, 11]. After $30 \mathrm{~min}$, the medium was replaced with fresh PBS with or without 2-aminoethoxydiphenyl borate (2APB; $20 \mu \mathrm{mol} / \mathrm{l}$; Sigma-Aldrich) or gallein $(10 \mu \mathrm{mol} / \mathrm{l}$; Santa Cruz Biotechnology, Santa Cruz, CA, USA) and incubated for a further $30 \mathrm{~min}$. Levels of intracellular free $\mathrm{Ca}^{2+}$ $\left(\left[\mathrm{Ca}^{2+}\right]_{\mathrm{i}}\right)$ were observed with a Nikon Eclipse TS 100 fluorescence imaging system (Nikon, Melville, NY, USA), and quantified with InCyt Im2 software (University of Cincinnati, Cincinnati, OH, USA). The number of cells observed was 10-20 per well.

\section{Immunoblotting}

Cells were lysed in immunoprecipitation buffer, and immunoblotting was performed as described previously [11]. Individual proteins were detected with primary antibodies against the phosphorylated form of extracellular signal-regulated kinase 1/2 (ERK 1/2) (1:1,000 dilution; Cell Signaling, Danvers, MA, USA) and total ERK (1:5,000 dilution; Santa Cruz Biotechnology), and visualised by enhanced chemiluminescence. Signals were quantified by densitometry coupled with ImageQuant software (Molecular Dynamics, Sunnyvale, CA, USA) and Scion Image (Scioncorp, Frederick, MD, USA).

\section{Membrane preparation and labelling and immunoprecipitation of membrane-associated G- proteins}

Cell membranes were purified as described previously [11,30]. Aliquots of purified membranes (70-100 g protein) were incubated for $10 \mathrm{~min}$ at $25^{\circ} \mathrm{C}$ with $185-370 \mathrm{GBq}$ $\left.{ }^{32} \mathrm{P}\right] \mathrm{GTP}$-azidoanilide (ALT, Lexington, KY, USA) in the absence or presence of different concentrations of DB. Specific Ga proteins were immunoprecipitated with antibodies against Gagust (Santa Cruz Biotechnology) and $\mathrm{Ga}_{\mathrm{i1}, 2}$ (Affinity BioReagents, Golden, $\mathrm{CO}$, USA). 


\section{Secretion of GLP-I from intact duodenum in vivo}

The duodenum was physically isolated from the stomach and the intestinal tract by clamps placed at the gastroduodenal junction and within the duodenum $\sim 5 \mathrm{~cm}$ distal to the gastroduodenal junction. The duodenum was flushed with $20 \mathrm{ml}$ Hanks' balanced salt solution (HBSS, calcium- and magnesium-free), and the proximal $5 \mathrm{~cm}$ of duodenum was dissected out and placed in culture medium. Tissues were incubated in $5 \% \mathrm{CO}_{2}$ for $1 \mathrm{~h}$ at $37^{\circ} \mathrm{C}$, before the addition of various concentrations of DB $(0,5$ and $10 \mathrm{mmol} / \mathrm{l})$ directly into the lumen of the duodenum. Medium was collected after $1 \mathrm{~h}$, and GLP-1 levels were assayed by ELISA (EMD Millipore).

\section{Animals}

Eight-week-old male Lepr-/- $(d b / d b)$ mice and C57BL/6 were purchased from Daehan Biolink (DBL, Eumseoung-gun, Chungcheongbuk-do, South Korea). All mice were acclimated for 1 week in a room with a light/dark cycle of $12 \mathrm{~h}$ at a temperature ranging from $21^{\circ} \mathrm{C}$ to $23^{\circ} \mathrm{C}$ and moderate humidity (55-60\%). Food and water were provided ad libitum. All animal study protocols were approved by the Institutional Animal Care and Use Committee (IACUC) of Kyung Hee University.

\section{OGTT}

Mice were fasted for $18 \mathrm{~h}$ before OGTT experiments. Each mouse group was orally administered saline or $1 \mathrm{mg} / \mathrm{kg}$ DB just before glucose gavage $(5 \mathrm{~g} / \mathrm{kg})$. Blood glucose was measured from the tail vein using the Accu-Chek Performa system (Roche Diagnostics, Mannheim, Germany) at six time points: 0 (before glucose gavage), 10 (10 min after glucose gavage), 20, 40, 90 and 120 min.

\section{Multiplex assay}

Mice were fasted for $18 \mathrm{~h}$ before experiments. Each mouse group was orally administered saline or $1 \mathrm{mg} / \mathrm{kg}$ DB just before glucose gavage $(2 \mathrm{~g} / \mathrm{kg})$. The blood collected from tail veins was immediately transferred into EDTA-coated microcentrifuge tubes containing dipeptidyl peptidase IV inhibitor, and the plasma was carefully separated into fresh tubes. A multiplex assay (Mouse Diabetes panel: GLP-1 and insulin; Bio-Rad, Hercules, CA, USA) was performed as described in the manufacturer's guide. The GLP-1 and insulin concentrations in each sample were measured with a Bio-Plex MAGPDC Multiplex reader (Bio-Rad). The results were analysed with Bio-Plex Manager software (Bio-Rad).

\section{Statistical analysis}

All in vitro experiments were repeated three times. GLP-1 and PYY data represent the mean \pm SEM. Significant differences between group values were analysed using one-way ANOVA and the post hoc Scheffé's test or Bonferroni's test. To measure the statistical significance between each in vivo group, two-way ANOVA with Bonferroni's post hoc test was performed. The in vivo experiments were repeated twice. Six to seven $d b / d b$ mice per group were used in the OGTT and multiplex experiments. Comparisons were performed using GraphPad Prism (GraphPad Software, San Diego, CA, USA). $p<0.05, p<0.01$ and $p<0.001$ were considered significant. 


\section{Results}

We found that DB and quinine stimulation of NCI-H716 cells resulted in the appearance of GLP-1 in the medium in a concentration-dependent manner (Fig. la). Using conventional PCR, we confirmed that NCI-H716 cells express GNAT3 mRNA [23] and then determined that these cells also express mRNAs for several bitter receptors (TAS2R3, TAS2R4 and TAS2R5) (Fig. lb). Because of the lack of suitable antibodies against TAS2R, the relative expression of TAS2R proteins could not be determined. We next determined total expression levels of the bitter taste receptor mRNAs using real-time quantitative PCR (Table 1). mRNA expression levels of the 25 human bitter taste receptors were compared with the expression of GNAT3, the Gagust-encoding gene, and expression levels for the TAS2Rs were normalised to the level of GAPDHmKNA expression.

We used the radioactive non-hydrolysable GTP analogue $\left[{ }^{32} \mathrm{P}\right]$ GTP-azidoanilide to investigate the presence of functional coupling of bitter taste receptors and G-proteins after DB treatment in the cell membranes from NCI-H716 cells. In untreated control membranes, there was constitutive GTP-azidoanilide incorporation into $\mathrm{Ga}_{\mathrm{i} 1,2}$ (Fig. 2b) without any effect on Gagust (Fig. 2a). Treatment with DB led to a dose-dependent increase in Gagust activation (Fig. 2a), which was apparent with DB concentrations as low as $0.5 \mathrm{mmol} / \mathrm{l}$. Under these conditions, Goa $_{\mathrm{i} 1,2}$ activation was markedly decreased, with $90 \%$ inhibition at $10 \mathrm{mmol} / \mathrm{l} \mathrm{DB}$ (Fig. 2b). Taken together, our findings provide the first direct indication of the involvement of specific G-proteins, known to be involved in bitter taste sensing, in this cell line.

To obtain further direct evidence of the involvement of bitter taste receptors in the mediation of DB-induced GLP-1 secretion, we used siRNAs directed against TAS2R4, TASR43, $T A S R 46$ and $G N A T S$ to reduce their expression levels. Our results show a decrease in GLP-1 secretion levels (Fig. 2c) when TAS2R4, TAS2R43, TAS2R46 or GNAT3 mRNA expression was reduced (Fig. 2d).

We then began to probe the downstream pathways by which activation of bitter taste receptors induces secretion of peptide hormones. We found that short-term incubation with phorbol 12-myristate 13-acetate (PMA), a potent activator of protein kinase $\mathrm{C}$ (PKC), mimicked the action of DB by increasing the secretion of both GLP-1 (Fig. 3a) and PYY (Fig. 3b) from NCI-H716 cells. Inhibition of PKC with bisindolylmaleimide I decreased DB-induced secretion of GLP-1 (Fig. 3c), supporting the hypothesis of a role for PKC in hormone release. We next determined whether cAMP and PDE were involved in GLP-1 secretion. We found that 3-isobutyl-1-methylxanthine (IBMX), a ubiquitous PDE inhibitor, inhibited DB-mediated GLP-1 secretion (Fig. 3d). To evaluate if DB-mediated secretion was PLC dependent, we assessed PLC's ability to modulate DB-induced secretion of GLP-1 in NCI-H716 cells. The GLP-1 response to DB was abrogated by PLC inhibition with U73122 in a concentration-dependent manner, while the inactive control, U73343, had no effect (Fig. 3e). Stimulation of bitter taste receptors also appears to activate ERK1/2, a well-described downstream target of PLC [31], because phospho-ERK levels were increased in response to increasing concentrations of DB (Fig. 3f). However, we found that PLC-mediated GLP-1 secretion by DB was not dependent on ERK activation because pharmacological inhibition 
of the ERK1/2 pathway with PD98059 foiled to attenuate DB-mediated secretion of GLP-1 (Fig. 3e). Taken together, these results indicate that NCI-H716 cells respond to bitter taste stimulation by releasing GLP-1 and PYY through involvement of both PLC and PDE signalling cascades (Fig. 3c).

We also looked for DB-induced increases in $\left[\mathrm{Ca}^{2+}\right]_{\mathrm{i}}$ in NCI-H716 cells, as would be expected with PLC activation. We used single cell imaging to monitor changes in the ' concentrations of $\left[\mathrm{Ca}^{24}\right]_{\mathrm{i}}$ in NCI-H716 cells loaded with a $\mathrm{Ca}^{2+}$ indicator dye. In the absence of extracellular calcium, DB treatment increased $\left[\mathrm{Ca}^{2+}\right]_{i}$ dose-dependently (Fig. 4a). Preincubation of the $\mathrm{G} \beta \gamma$ inhibitor, gallein, or the $\mathrm{IP}_{3}$ receptor antagonist, $2 \mathrm{APB}$, suppressed DB-mediated $\left[\mathrm{Ca}^{2+}\right]_{\mathrm{i}}$, release from the intracellular calcium stores (Fig. $4 \mathrm{~b}$ ). In addition, we found that DB time-dependently decreased intracellular cAMP levels (Fig. 4c). Quinine, a known potent bitter receptor activator, also decreased intracellular cAMP levels, and, as expected, the adenylyl cyclase (AC) activator, forskolin, caused a highly significant increase in cAMP levels, while SQ22536, an AC inhibitor, did not influence basal cAMP levels. Figure $4 \mathrm{~d}$ provides a summary of the molecular mechanisms operating in NCI-H716 cells that are involved in bitter taste-mediated GLP-1 secretion.

To find out if the findings from NCI-H716 cells have any direct bearing on L cells in situ, we examined GLP-1 secretion from isolated mouse duodena in response to DB. There was a 2.5-fold increase in GLP-1 release from isolated duodenal specimens into the bathing medium over non-stimulated levels after addition of $10 \mathrm{mmol} / \mathrm{l} \mathrm{DB}(p<0.001)$ for $1 \mathrm{~h}$ (Fig. $5)$.

Finally, we performed an in vivo study using $d b / d b$ mice to examine the physiological implication of the activation of gut-expressed bitter taste receptor. Mice were gavaged with glucose ( $5 \mathrm{~g} / \mathrm{kg}$ body weight) after the first gavage with $1 \mathrm{mg} / \mathrm{kg}$ DB. DB-treated $d b / d b$ mice had lower blood glucose levels 20 and $40 \mathrm{~min}$ after glucose gavage than the saline-treated group, which translated into lower AUC for glucose for the $120 \mathrm{~min}$ period after oral glucose (Fig. 6a, b). DB also increased plasma GLP-1 (Fig. 6c), which was probably the immediate cause of the increased insulin levels seen in the DB-treated animals (Fig. 6d).

\section{Discussion}

In this study, we confirm that NCI-H716 cells contain functional bitter taste receptors and that activation of these receptors by DB and quinine results in direct coupling to Gagust and subsequent GLP-1 and PYY secretion. Although much work remains to be carried out, we have also illuminated part of the bitter signalling pathway that results in GLP-1 and PYY secretion by DB.

We previously reported that glucose stimulates GLP-1 secretion from NCI-H716 cells [11]. The presence of specific G-protein subunits and other elements implicated in sensing of and response to sweet sensations in L cells of the intestine [11] led us to investigate whether bitter taste elements are also present in NCI-H716 cells. Approximately 25 human TAS2R genes have been identified, and many have overlapping agonist spectra, indicating redundancy in the human bitter taste receptor pathways [32]. We found that DB induces 
GLP-1 and PYY secretion in a concentration-dependent manner, and that the specific DBsensitive, bitter receptor, TAS2R4 [4,33], as well as other bitter receptors are expressed in NCI-H716 cells.

We also investigated the downstream signalling pathways known to be involved in bitter taste receptor activation. The secretion of GLP-1 and PYY was found to be PLC and PKC dependent and required an increase in $\left[\mathrm{Ca}^{2+}\right]_{\mathrm{i}}$ that resulted from activation of PLC. These results are in agreement with those obtained by Masuho et al [34], who reported that bitter tastants elicited responses through PLC pathways in mouse-derived intestinal STC-1 cells.

Our work with DB shows that stimulation of bitter taste receptors also results in the phosphorylation and activation of ERK, presumably mediated by PKC. This finding is corroborated by our previous work in NCI-H716 cells, which demonstrated that ERK is also activated when sucralose and glucose activate sweet taste receptors [11, 35]. However, pharmacological inhibition of the ERK pathway failed to inhibit the GLP-1 secretion elicited by DB and it is therefore likely that the ERK pathway is involved in growth, and not secretion, in NCI-H716 cells.

That the $\mathrm{L}$ cells in the gut would sense and respond to not only the nutrient content of food but also other chemical contents makes sense from a physiological perspective. In addition to being insulinotropic, GLP-1 slows gastric emptying and inhibits gastric motility [26, 27, 36]. In fact, under normal postabsorptive conditions, these are thought to be its major effects [37]. Therefore, bitter compounds might also be expected to induce GLP-1 secretion in order to prevent them from reaching the absorptive surfaces of enterocytes of the small bowel. Delayed gastric emptying would also lead to distension and subsequent emesis of the offending compound, and a feeling of satiety coupled with distension would lessen input of more of the substance. Therefore, induced increase in GLP-1 by bitter tastants may have an important role in host defence through reduction of toxic food intake.

The other products of the L cell-GLP-2 and PYY - also have significant physiological effects. PYY is released postprandially and inhibits gastric, pancreatic and intestinal secretions [38, 39], as well as gastrointestinal motility [24, 25]. Although the initial finding by Batterham et al [28] that PYY is a satiety factor has been difficult to replicate, PYY is nevertheless a putative satiety factor. Therefore, the secretion of PYY would also have beneficial effects on lessening intake of the toxic substance. Intriguingly, GLP-1 and PYY have been found to mediate conditioned taste aversion in mice [40,41], a function that was not easily intuited on the basis of these peptides being involved in the assimilation of food and the regulation of rates of gastric emptying and gut motility.

From a pharmacological perspective, the blood glucose-lowering effect of DB, through stimulation of GLP-1 secretion, implies that gut-expressed bitter taste receptors are eminently worthy of study. Compounds that activate these receptors in gut, such as a procompound that would be activated on entering the stomach, and that do not elicit a bitter perception at the level of taste, may counteract the hedonic effect of food, and indeed might actually induce an aversive response to food intake and activate satiety mechanisms. Further work on humans in vivo is needed to uncover the significance of these findings. 


\section{Supplementary Material}

Refer to Web version on PubMed Central for supplementary material.

\section{Acknowledgments}

This research was supported by Kyung Hee University (KHU-20130547) and the Basic Science Research Program through the National Research Foundation of Korea (NRF) funded by the Ministry of Education, Science and Technology (2012-0005755 and NRF-2013R1 Al A2004960). Some of the data in this paper were presented as a poster abstract at the Fourth International Congress on Prediabetes and Metabolic Syndrome in 2011.

Funding This work was supported by the Intramural Research Program of the National Institute on Aging/National Institutes of Health and by National Institute on Deafness and Other Communication Disorders/National Institutes of Health (grants DC003055).

\section{Abbreviations}

AC

2APB 2-Aminoethoxydiphenyl borate

$\left[\mathrm{Ca}^{2+}\right]_{\mathbf{i}} \quad$ mtracellular free $\mathrm{Ca}^{2+}$

DAG Diacylglycerol

DB Denatonium benzoate

ERK Extracellular signal-regulated kinase

Gagust a-Gustducin

GLP-1 Glucagon-like peptide-1

HBSS Hanks' balanced salt solution

IBMX 3-Isobutyl-1-methylxanthine

IP3 Inositol 1,4,5-trisphosphate

PDE Phosphodiesterase

PKC Protein kinase C

PLC Phospholipase C

PMA Phorbol 12-myristate 13-acetate

PYY Peptide YY

siRNA Small interfering RNA

TAS1 Rs Sweet and umami taste receptors

TAS2Rs Bitter taste receptors 


\section{References}

1. Margolskee RF. Molecular mechanisms of bitter and sweet taste transduction. J Biol Chem. 2002; 277:1-4. [PubMed: 11696554]

2. Matsunami H, Montmayeur JP, Buck LB. A family of candidate taste receptors in human and mouse. Nature. 2000; 404:601-604. [PubMed: 10766242]

3. Miller, IJ, Jr. Handbook of Olfaction and Gustation. New York: Dekker; 1995. Anatomy of the peripheral taste system.

4. Pronin AN, Tang H, Connor J, Keung W. Identification of ligands for two human bitter T2R receptors. Chem Senses. 2004; 29:583-593. [PubMed: 15337684]

5. Nelson G, Hoon MA, Chandrashekar J, Zhang Y, Ryba NJ, Zuker CS. Mammalian sweet taste receptors. Cell. 2001; 106:381-390. [PubMed: 11509186]

6. Wong GT, Gannon KS, Margolskee RF. Transduction of bitter and sweet taste by gustducin. Nature. 1996; 381:796-800. [PubMed: 8657284]

7. Ming D, Ruiz-Avila L, Margolskee RF. Characterization and solubilization of bitter-responsive receptors that couple to gustducin. Proc Natl Acad Sci U S A. 1998; 95:8933-8938. [PubMed: 9671782]

8. Shin M-H, Suh H-W, Lee K-B, et al. Gentiana scabra extracts stimulate glucagon-like peptide-1 secretion via $G$ protein-coupled receptor pathway. BioChip J. 2012; 6:114-119.

9. Reimer RA, Darimont C, Gremlich S, Nicolas-Metral V, Ruegg UT, Mace K. A human cellular model for studying the regulation of glucagon-like peptide-1 secretion. Endocrinology. 2001; 142:4522-4528. [PubMed: 11564718]

10. Dyer J, Salmon KS, Zibrik L, Shirazi-Beechey SP. Expression of sweet taste receptors of the T1R family in the intestinal tract and enteroendocrine cells. Biochem Soc Trans. 2005; 33:302-305. [PubMed: 15667333]

11. Jang HJ, Kokrashvili Z, Theodorakis MJ, et al. Gut-expressed gustducin and taste receptors regulate secretion of glucagon-like peptide-1. Proc Natl Acad Sci U S A. 2007; 104:15069-15074. [PubMed: 17724330]

12. Rozengurt N, Wu S, Chen MC, Huang C, Sternini C, Rozengurt E. Colocalization of the alphasubunit of gustducin with PYY and GLP-1 in L cells of human colon. Am J Physiol Gastrointest Liver Physiol. 2006; 291:G792-G802. [PubMed: 16728727]

13. Wu SV, Rozengurt N, Yang M, Young SH, Sinnett-Smith J, Rozengurt E. Expression of bitter taste receptors of the T2R family in the gastrointestinal tract and enteroendocrine STC-1 cells. Proc Natl Acad Sci U S A. 2002; 99:2392-2397. [PubMed: 11854532]

14. Wu SV, Chen MC, Rozengurt E. Genomic organization, expression, and function of bitter taste receptors (T2R) in mouse and rat. Physiol Genomics. 2005; 22:139-149. [PubMed: 15886333]

15. Adachi T, Tanaka T, Takemoto K, Koshimizu TA, Hirasawa A, Tsujimoto G. Free fatty acids administered into the colon promote the secretion of glucagon-like peptide- 1 and insulin. Biochem Biophys Res Commun. 2006; 340:332-337. [PubMed: 16356474]

16. Diakogiannaki E, Pais R, Tolhurst G, et al. Oligopeptides stimulate glucagon-like peptide-1 secretion in mice through proton-coupled uptake and the calcium-sensing receptor. Diabetologia. 2013; 56:2688-2696. [PubMed: 24045836]

17. Reimann F, Gribble FM. Glucose-sensing in glucagon-like peptide-1-secreting cells. Diabetes. 2002; 51:2757-2763. [PubMed: 12196469]

18. Reimann F, Williams L, da Silva Xavier G, Rutter GA, Gribble FM. Glutamine potently stimulates glucagon-like peptide-1 secretion from GLUTag cells. Diabetologia. 2004; 47:1592-1601. [PubMed: 15365617]

19. Gribble FM, Williams L, Simpson AK, Reimann F. A novel glucose-sensing mechanism contributing to glucagon-like peptide-1 secretion from the GLUTag cell line. Diabetes. 2003; 52:1147-1154. [PubMed: 12716745]

20. Dotson CD, Zhang L, Xu H, et al. Bitter taste receptors influence glucose homeostasis. PLoS One. 2008; 3:e3974. [PubMed: 19092995] 
21. Kim KS, Cha NH, Kim KW, et al. Transcriptomic analysis of the bitter taste receptor-mediated glucagon-like peptide-1 stimulation effect of quinine. BioChip J. 2013; 7:386-392.

22. Drucker DJ. Glucagon-like peptide-1 and the islet beta-cell: augmentation of cell proliferation and inhibition of apoptosis. Endocrinology. 2003; 144:5145-5148. [PubMed: 14645210]

23. Drucker DJ. Enhancing incretin action for the treatment of type 2 diabetes. Diabetes Care. 2003; 26:2929-2940. [PubMed: 14514604]

24. Gehlert DR. Multiple receptors for the pancreatic polypeptide (PP-fold) family: physiological implications. Proc Soc Exp Biol Med. 1998; 218:7-22. [PubMed: 9572148]

25. Deng X, Wood PG, Sved AF, Whitcomb DC. The area postrema lesions alter the inhibitory effects of peripherally infused pancreatic polypeptide on pancreatic secretion. Brain Res. 2001; 902:18 29. [PubMed: 11376591]

26. Imeryuz N, Yegen BC, Bozkurt A, Coskun T, Villanueva-Penacarrillo ML, Ulusoy NB. Glucagonlike peptide-1 inhibits gastric emptying via vagal afferent-mediated central mechanisms. Am J Physiol. 1997; 273:G920-G927. [PubMed: 9357836]

27. Gutzwiller JP, Drewe J, Goke B, et al. Glucagon-like peptide-1 promotes satiety and reduces food intake in patients with diabetes meffitus type 2. Am J Physiol. 1999; 276:R1541-R1544. [PubMed: 10233049]

28. Batterham RL, Cowley MA, Small CJ, et al. Gut hormone PYY(3-36) physiologically inhibits food intake. Nature. 2002; 418:650-654. [PubMed: 12167864]

29. Choi E-K, Kim K-S, Yang HJ, et al. Hexane fraction of Citrus aurantium L. stimulates glucagonlike peptide-1 (GLP-1) secretion via membrane depolarization in NCI-H716 cells. BioChip J. 2012; 6:41-47.

30. Monirose-Rafizadeh C, Avdonin P, Garant MJ, et al. Pancreatic glucagon-like peptide-1 receptor couples to multiple $\mathrm{G}$ proteins and activates mitogen-activated protein kinase pathways in Chinese hamster ovary cells. Endocrinology. 1999; 140:1132-1140. [PubMed: 10067836]

31. Marinissen MJ, Gutkind JS. G-protein-coupled receptors and signaling networks: emerging paradigms. Trends Pharmacol Sci. 2001; 22:368-376. [PubMed: 11431032]

32. Meyerhof W. Elucidation of mammalian bitter taste. Rev Physiol Biochem Pharmacol. 2005; 154:37-72. [PubMed: 16032395]

33. Behrens M, Meyerhof W. Signaling in the chemosensory systems: bitter taste receptors and human bitter taste perception. Cell Mol Life Sci. 2006; 63:1501-1509. [PubMed: 16732425]

34. Masuho I, Tateyama M, Saitoh O. Characterization of bitter taste responses of intestinal STC-1 cells. Chem Senses. 2005; 30:281-290. [PubMed: 15741596]

35. Reimer RA. Meat hydrolysate and essential amino acid-induced glucagon-like peptide-1 secretion, in the human NCI-H716 enteroendocrine cell line, is regulated by extracellular signal-regulated kinasel/2 and p38 mitogen-activated protein kinases. JEndocrinol. 2006; 191:159-170. [PubMed: 17065399]

36. Meier JJ. GLP-1 receptor agonists for individualized treatment of type 2 diabetes melhtus. Nat Rev Endocrinol. 2012; 8:728-742. [PubMed: 22945360]

37. Hall WL, Millward DJ, Long SJ, Morgan LM. Casein and whey exert different effects on plasma amino acid profiles, gastrointestinal hormone secretion and appetite. Br J Nutr. 2003; 89:239-248. [PubMed: 12575908]

38. Adrian TE, Ferri GL, Bacarese-Hamilton AJ, Fuessl HS, Polak JM, Bloom SR. Human distribution and release of a putative new gut hormone, peptide YY. Gastroenterology. 1985; 89:1070-1077. [PubMed: 3840109]

39. Greeley GH Jr, Hashimoto T, Izukura M, et al. A comparison of intraduodenally and intracolonically administered nutrients on the release of peptide-YY in the dog. Endocrinology. 1989; 125:1761-1765. [PubMed: 2791964]

40. Talsania T, Anini Y, Siu S, Drucker DJ, Brubaker PL. Peripheral exendin-4 and peptide YY(3-36) synergistically reduce food intake through different mechanisms in mice. Endocrinology. 2005; 146:3748-3756. [PubMed: 15932924]

41. Halatchev IG, Cone RD. Peripheral administration of PYY(3-36) produces conditioned taste aversion in mice. Cell Metab. 2005; 1:159-168. [PubMed: 16054059] 


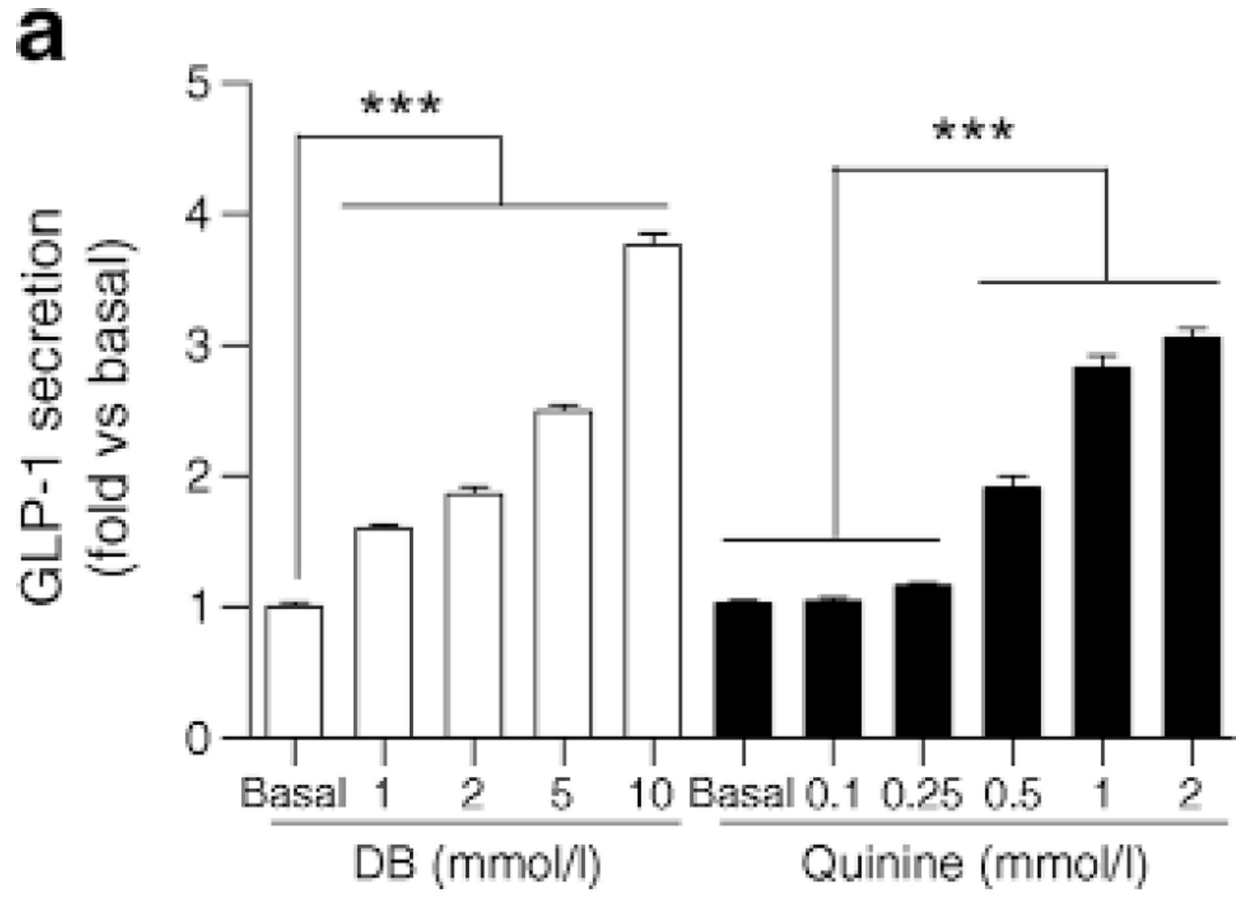

b

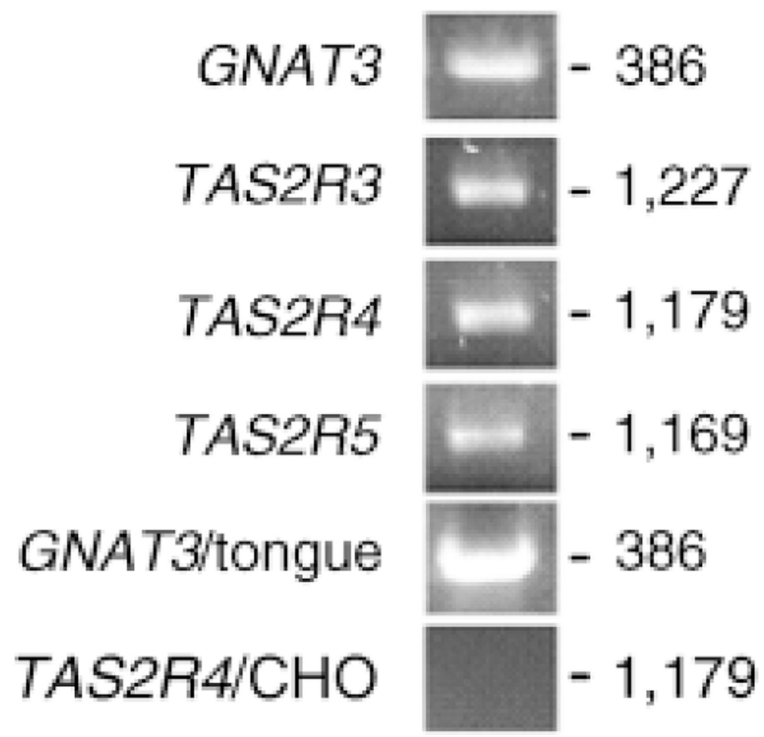

Fig. 1.

GLP-1 secretion from NCI-H716 cells in response to bitter tastants. (a) GLP-1 secretion from NCI-H716 cells treated wife DB or quinine. Data are expressed as mean \pm SEM. $* * * p<0.001$. (b) Expression of bitter taste receptor mRNAs in NCI-H716 cells determined by conventional PCR (first to fourth band). GNAT3/tongue was used as a positive control and TAS2R 4/CHO cell was used as a negative control. Numbers indicate size of PCR products 
a
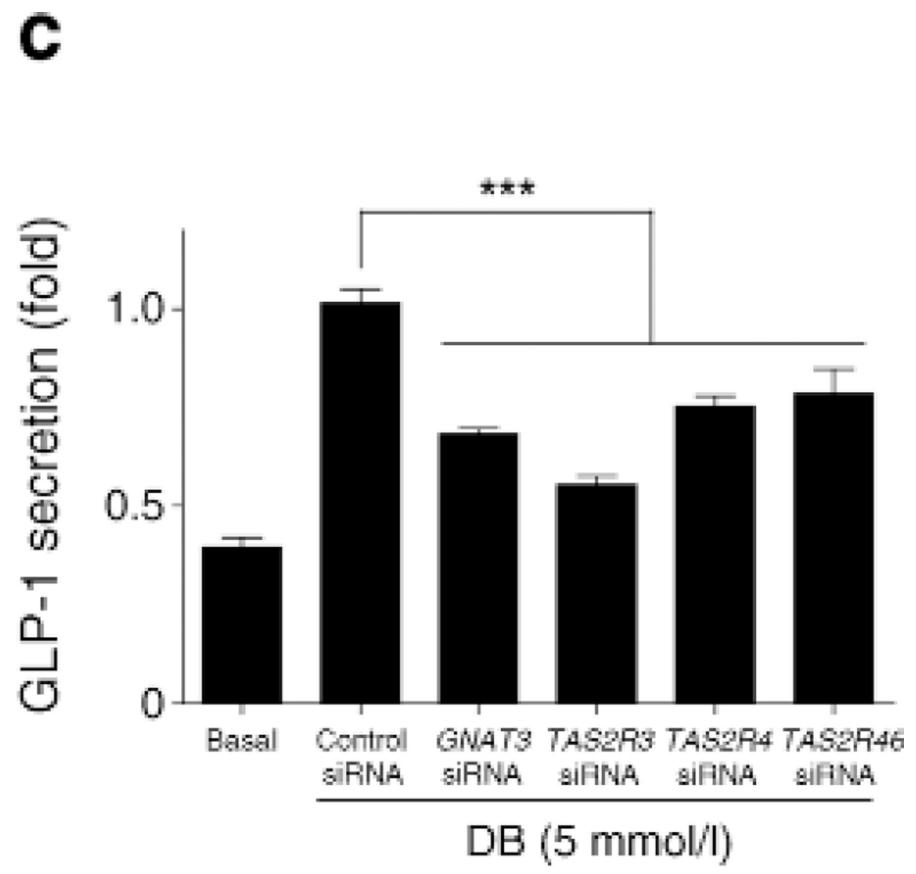

d

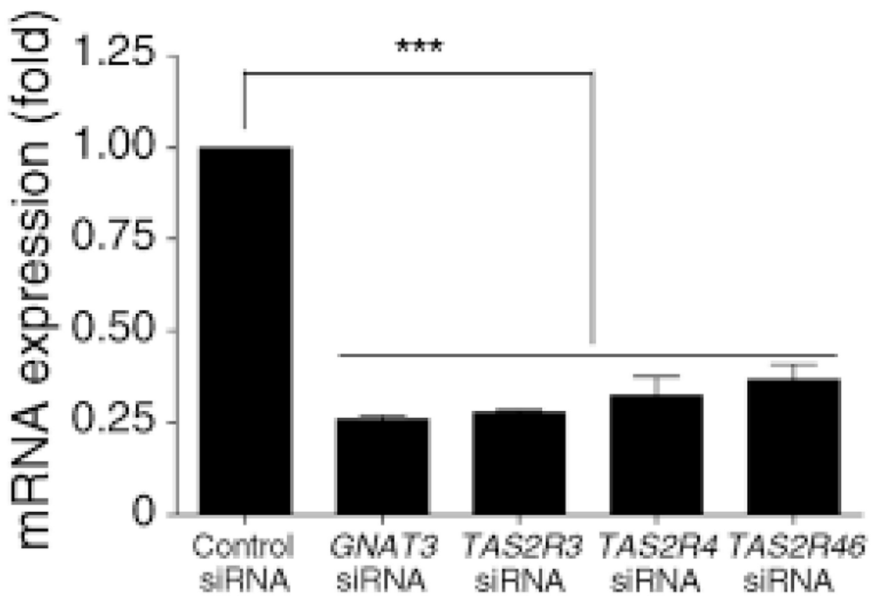

Fig. 2.

Coupling of fee bitter taste receptors to G-protein a-subunits in NCI-H716 cells, (a, b) DB increased the binding of [ $\left.{ }^{32} \mathrm{P}\right]$ GTP-azidoanilide to Gocgust (a) while decreasing binding to $\mathrm{Ga}_{\mathrm{i} 1,2}$ (b) in a concentration-dependent manner, (c, d) GNAT3, TAS2R4, TAS2R43 and $T A S 2 R 46$ siRNAs reduced DB-induced GLP-1 secretion. Data are expressed as mean \pm SEM. $* * * p<0.001$ 

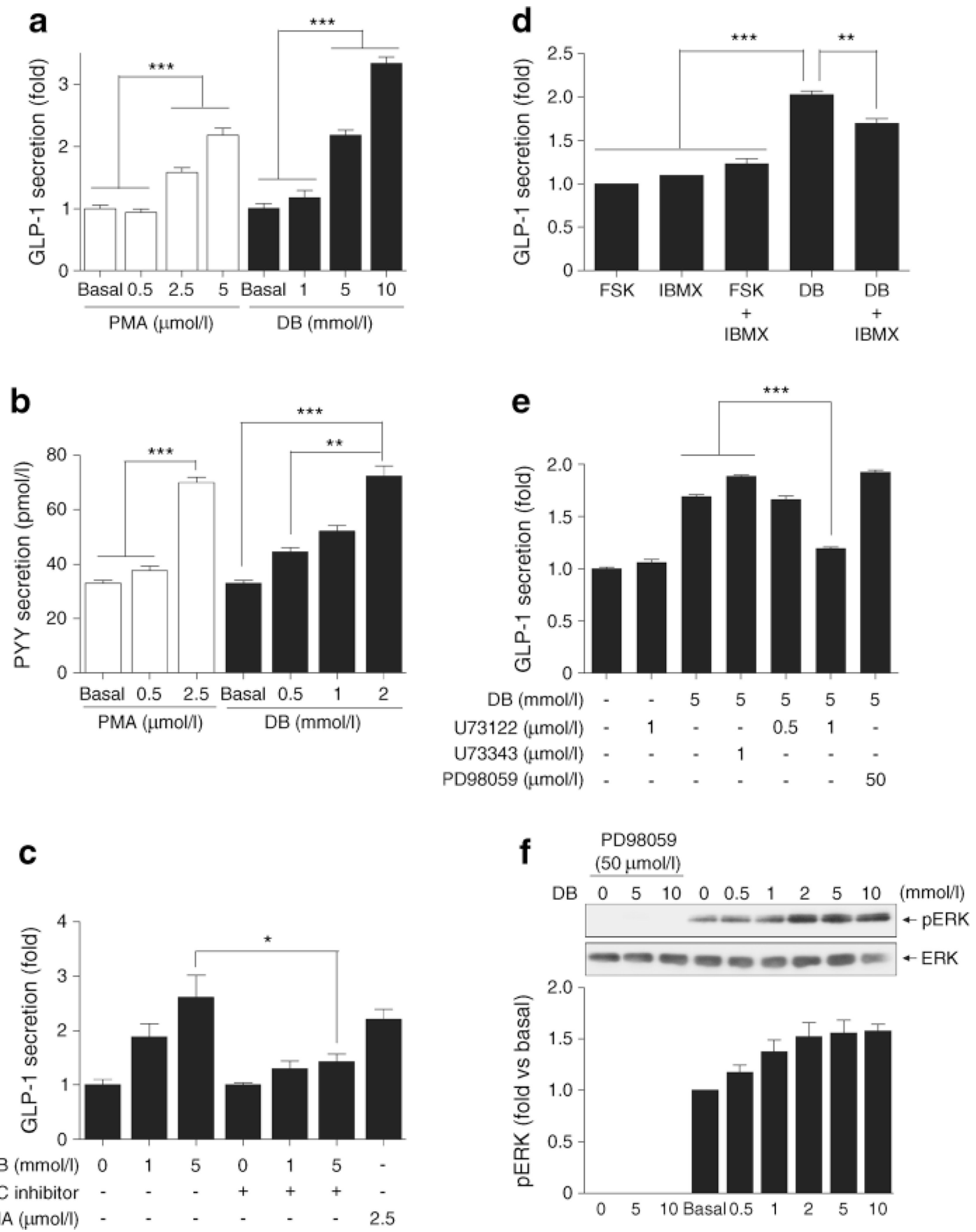

Fig. 3.

Downstream signalling of DB-mediated GLP-1 secretion in NCI-H716 cells, (a-c) GLP-1 and PYY secretion in response to DB, PMA and PKC inhibition, (d) GLP-1 secretion in the presence of forskolin (FSK) or DB, with and without PDE inhibition by BMX. (e) DBmediated GLP-1 secretion in the presence of PKC or ERK1/2 inhibition with U73122orPD98059, respectively, (f) Representative immunoblot of ERK phosphorylation in response to increasing concentrations of DB: bars denote the pERK signal normalised to that of total ERK. Results are mean \pm SEM. $* p<0.05, * * p<0.01, * * * p<0.001$ 

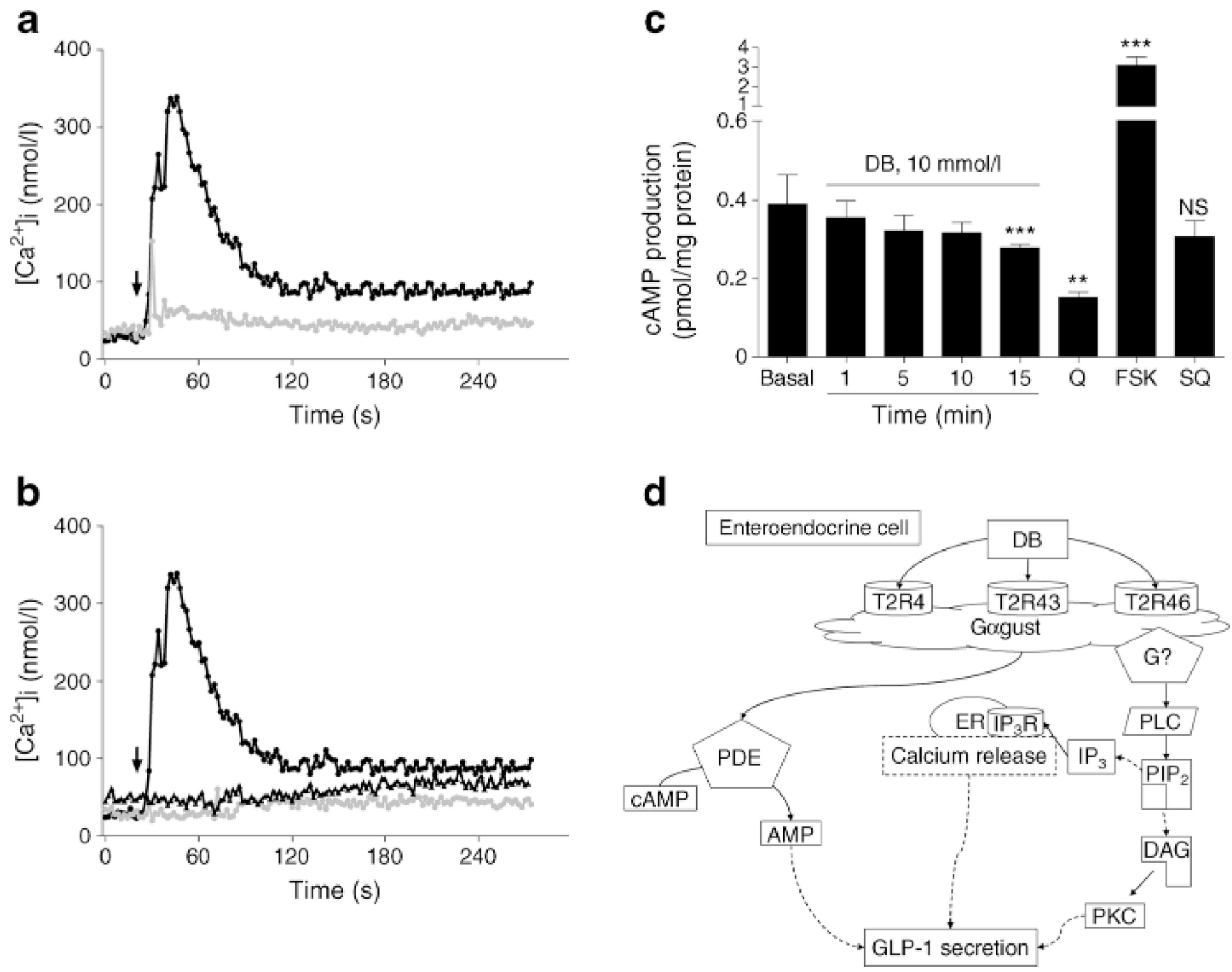

Fig. 4.

DB increased $\left[\mathrm{Ca}^{2+}\right]_{\mathrm{i}}$ and decreased cAMP levels in NCI-H716 cells, (a, b) Arrows indicate DB applications. $\left[\mathrm{Ca}^{2+}\right]_{\mathrm{i}}$ increase in response to DB $10 \mathrm{mmol} / \mathrm{l}$ (black circles) or DB 5 $\mathrm{mmol} / \mathrm{l}$ (grey circles) was compared (a) and in the presence of $\mathrm{Ga} \gamma$ or $\mathrm{IP}_{3}$ receptor inhibition with gallein (black triangles) or 2APB (grey circles) in (b). (c) Intracellular cAMP accumulation in response to DB, quinine and adenylate cyclase activation (FSK) and inhibition (SQ). (d) Schema of putative molecular pathways involved in DB-mediated GLP-1 secretion. Results are mean \pm SEM. ** $p<0.01$, *** $p<0.001$ vs basal. $\mathrm{IP}_{3} \mathrm{R}, \mathrm{IP}_{3}$ receptor; $\mathrm{PIP}_{2}$, phosphatidylinositol 4,5-bisphosphate; Q, quinine; $\mathrm{SQ}$, SQ22536 


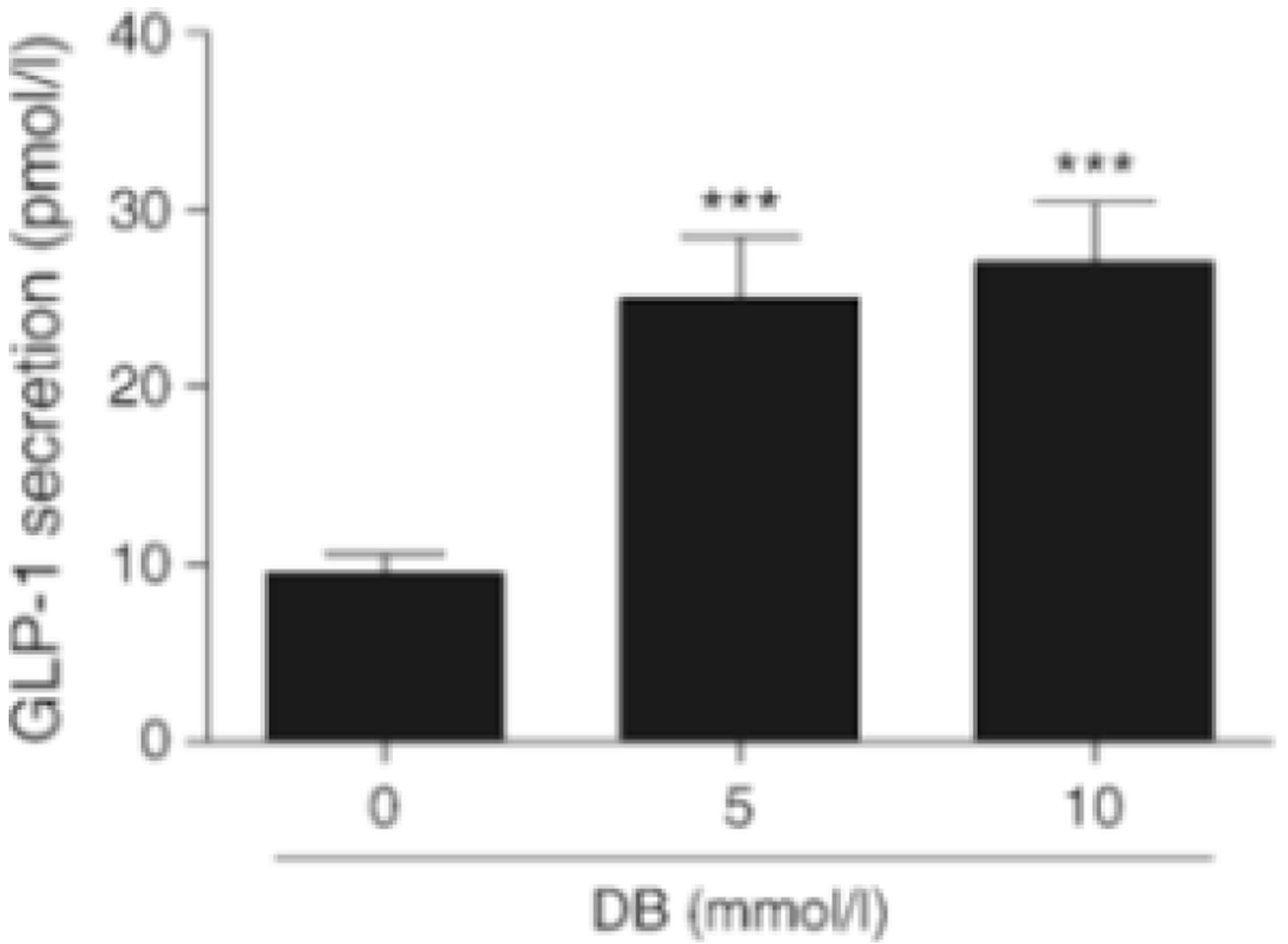

Fig. 5.

GLP-1 secretory responses to DB from isolated proximal duodenum of mice. Values are expressed as mean \pm SEM. $* * * p<0.001$ 
a
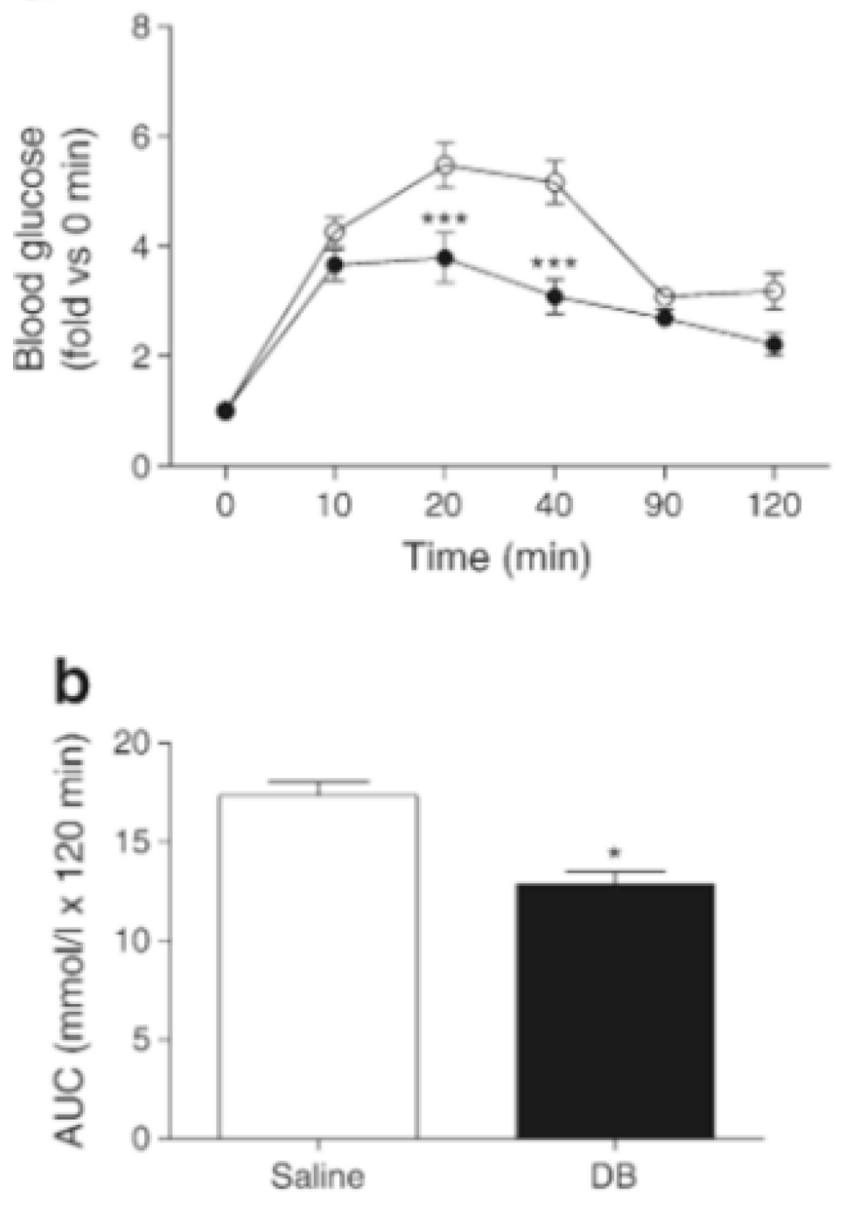

C
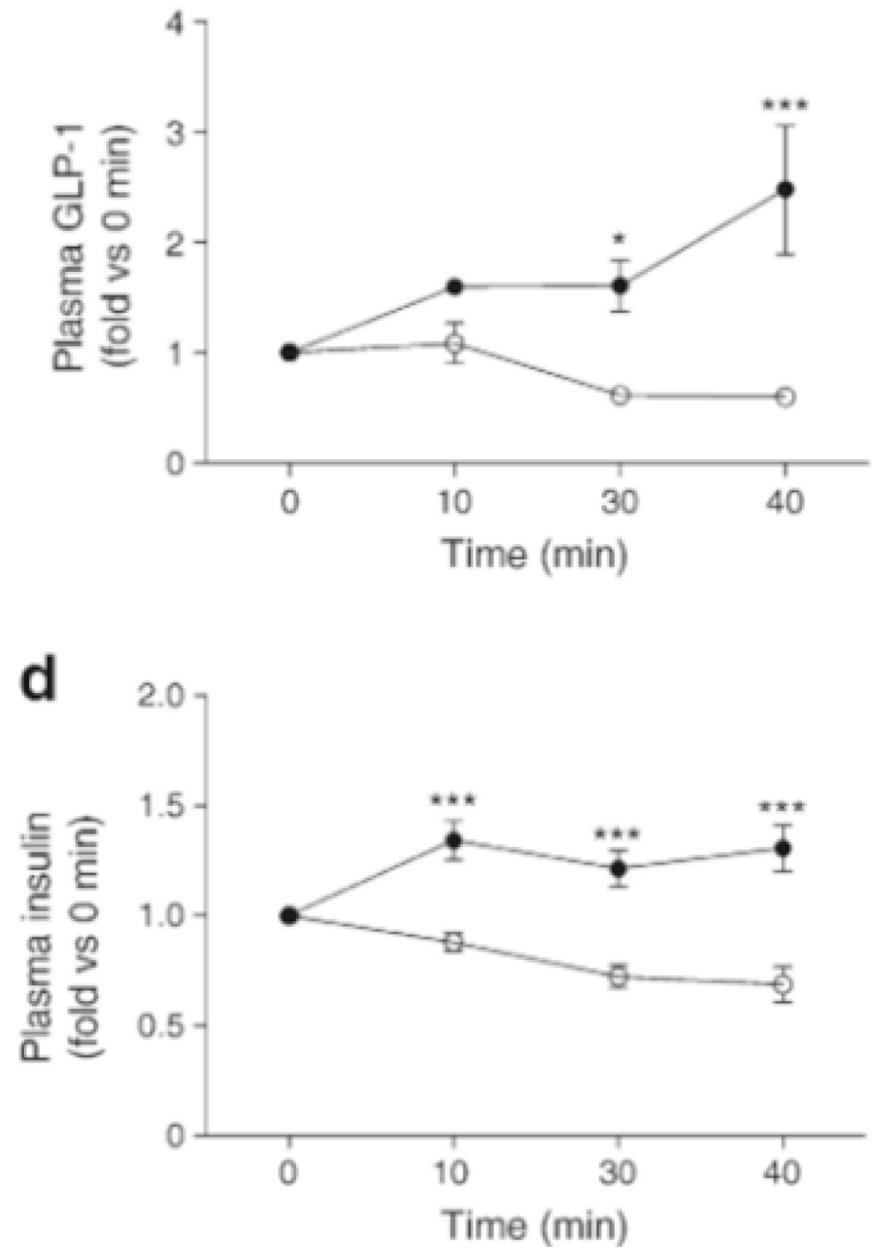

Fig. 6.

DB modulates blood glucose levels by increasing GLP-1 secretion in $d b / d b$ mice, (a) Blood glucose levels in DB-(black circles) and saline- (white circles) treated $d b / d b$ mice after glucose gavage ( $5 \mathrm{~g} / \mathrm{kg}$ body weight), (b) AUC (120 $\mathrm{min}$ ) of blood glucose after glucose gavage. (c, d) Plasma GLP-1 and insulin levels after glucose gavage ( $2 \mathrm{~g} / \mathrm{kg}$ body weight). $n=6-7$ animals. Values are expressed as mean \pm SEM. $* p<0.05, * * * p<0.001$ 


\section{Table 1}

mRNA expression of bitter taste receptors in human enteroendocrine NCI-H716 cells

\begin{tabular}{ll}
\hline Gene & Ratio to GNAT3 \\
\hline TAS2R2O & $8.406 \pm 1.160$ \\
TAS2R43 & $5.421 \pm 0.043$ \\
TAS2R31 & $5.294 \pm 0.088$ \\
TAS2R19 & $2.814 \pm 0.180$ \\
TAS2R14 & $2.796 \pm 0.047$ \\
TAS2R46 & $2.786 \pm 0.812$ \\
TAS2R45 & $2.195 \pm 0.390$ \\
TAS2R3 & $1.368 \pm 0.149$ \\
TAS2R5O & $1.092 \pm 0.229$ \\
TAS2R13 & $0.858 \pm 0.220$ \\
TAS2R10 & $0.725 \pm 0.096$ \\
TAS2R42 & $0.339 \pm 0.006$ \\
TAS2R5 & $0.329 \pm 0.020$ \\
TAS2R30 & $0.241 \pm 0.070$ \\
TAS2R38 & $0.203 \pm 0.033$ \\
TAS2R4O & $0.101 \pm 0.027$ \\
TAS2R39 & $0.084 \pm 0.007$ \\
TAS2R9 & $0.044 \pm 0.004$ \\
TAS2R4 & $0.041 \pm 0.001$ \\
TAS2R7 & $0.030 \pm 0.004$ \\
TAS2R60 & $0.016 \pm 0.003$ \\
TAS2R16 & $0.015 \pm 0.003$ \\
TAS2R8 & $0.013 \pm 0.001$ \\
TAS2R41 & $0.011 \pm 0.001$ \\
TAS2R1 & $0.008 \pm 0.002$ \\
GNAT3 & $1.0(\mathrm{reference)}$ \\
\hline &
\end{tabular}

Real-time quantitative PCR results were normalised to expression of $G A P D H$, and then the expression level of each bitter taste receptor mRNA was compared with that of GNAT3, which encodes Gagust. Results are from three to five individual experiments performed in triplicate. Values are mean \pm SEM 